Tohoku J. Exp. Med., 2008, 215, 71-77

\title{
School Children's Salt Intake Is Correlated with Salty Taste Preference Assessed by Their Mothers
}

\author{
Hiroe Matsuzuki, ${ }^{1,2}$ Takashi Muto ${ }^{2}$ and Yasuo Haruyama ${ }^{2}$ \\ ${ }^{1}$ Faculty of Home Economics, Tokyo Kasei Gakuin University, Machida, Japan \\ ${ }^{2}$ Department of Public Health, Dokkyo Medical University School of Medicine, Tochigi, Japan
}

\begin{abstract}
Salt intake in childhood is a risk factor for developing hypertension later in life. As health education for children to decrease salt intake, it is important for them to know the relationship between salty taste preference and salt intake. The objective of this study was to investigate the relationship between children's salty taste preference and their salt intake. We employed a cross-sectional study design, and the subjects were 199 elementary school children (5th or 6th grade) and their mothers. The amount of salt intake was estimated by the amount of urinary sodium excretion. Children's salty taste preference was assessed 1) by asking children about their own salty taste preference as well as measuring their threshold level of salty taste, and 2) by their mothers' observation of their salt intake behavior using a questionnaire. The salt intake and salt taste threshold of children who liked a salty taste were similar to those in children who disliked it. No association was found between the threshold level of salty taste and sodium intake. Regarding the relationship between children's salt intake and their salt intake behavior score, assessed by their mothers using a questionnaire, the high score group had a higher estimated salt intake than the low score group. In conclusion, children's salt intake may be accurately assessed by their mother's observation rather than children's own salty taste preference. This study suggests the importance of a mother's role in salt restriction education for children. —— salty taste preference; salt intake; sodium excretion; health education; mothers' roles.

Tohoku J. Exp. Med., 2008, 215 (1), 71-77.
\end{abstract}

(C) 2008 Tohoku University Medical Press

Excess salt intake can be detrimental to overall health and mortality, as salt intake is directly related to blood pressure and increases the risk of cardiovascular disease and stroke (Frost et al. 1981; Tuomilehto et al. 1981; Ikeda et al. 1986; Intersalt Cooperative Research Group 1988; Tuomilehto et al. 1989; Michael et al. 1998; Chobanian and Hill 2000; Kaplan 2000; Nagata et al. 2004). There is now increasing evidence that salt intake in childhood is a risk factor for developing hypertension later in life (Danise and
Simons 1997; Antonios 2000). Salt is often ingested in excess of physiological need, particularly in industrialized countries. In Japan, the National Health and Nutrition Survey in 2004 reported that an average adult's salt intake was $11.2 \mathrm{~g} /$ day (Ministry of Health, Labor and Welfare 2006), although the Ministry of Health, Labor and Welfare recommends reducing the average adult salt intake to below $10 \mathrm{~g} /$ day. It also recommends that children should become accustomed to eating low-salt food.

Received December 12, 2007; revision accepted for publication March 18, 2008.

Correspondence: Hiroe Matsuzuki, Faculty of Home Economics, Tokyo Kasei Gakuin University, 2600 Aihara-cho, Machida, Tokyo 194-0292, Japan.

e-mail: mtzkhiro@kasei-gakuin.ac.jp 
From the standpoint of health education for children to decrease their salt intake, it is important for them to know the relationship between salty taste preference and salt intake. Children will restrict their salty food intake if they know that the more they like salty food, the more salt they will ingest; however, few studies have examined the relationship between salty taste preference and salt intake by children. We hypothesized that children's salty taste preference is associated with their salt intake. Children who like a salty taste may have a higher salt intake than those who dislike it. The objective of this study was to investigate the relationship between children's salty taste preference and their salt intake.

\section{Methods}

\section{Study design and subjects}

This survey was a cross-sectional study. Subjects were all 5th and 6th grade elementary school children aged $10-12$ years $(n=251)$ at two elementary schools chosen from urban and rural areas of the Kanto region in Japan. The aim and procedure of this survey were explained to their mothers by class teachers and school nurses in May 2004. Among them, 199 children (108 girls and 91 boys) and their mothers $(79.3 \%$ of all subjects) gave written informed consent to participate in this study. This study was approved by the Tokyo Kasei Gakuin University Ethics Committee.

\section{Procedure}

Height and weight were measured according to standardized procedures at regular health checks stipulated by the School Health Law. The amount of salt intake was estimated by the amount of urinary sodium excretion. Urinary sodium excretion was estimated from second morning voiding urine specimen using Kawasaki's method (Kawasaki et al. 1993). Urinary sodium was measured by the ion selective electrode method, and urinary creatinine was measured by Creatiniase (Sarcosine Oxidase/POD) at Mitsubishi-kagaku Bio-Clinical Laboratories Inc. (Tokyo).

The children's salty taste preference was assessed by two methods. Children were asked about their salty taste preference using a multiple choice question with three possible answers: dislike, no preference or like. Because we are not sure whether children of this age can accurately assess their own salty taste preference, we measured their threshold level of salty taste in order to support the validity of their taste preference. In adults, salty taste preference is associated with the salt taste threshold level (Zumkley 1987; Beauchamp and Engelman 1991; Okoro et al. 1998; Serafin 2004), and we hypothesized that this association would also be found in children. Children who liked a salty taste might have a higher salt taste threshold level. To measure the children's threshold level of salty taste, we used a slip of paper called Salsave (Advantech Toyo Co., Fukuoka), impregnated with several salt concentrations $(0.6 \%$ to 1.6\%) (Nishimoto et al. 1996, 2005). After rinsing their mouth with mineral water, the Salsave paper impregnated with $0 \%$ salt was placed on the front-center of the subject's tongue for three seconds, followed by the same procedure using paper with $0.6 \%$ salt. Subjects were asked whether they were able to distinguish $0.6 \%$ from $0 \%$. If they could not distinguish between them, a higher salt concentration was used until they could. The lowest concentration determined by these procedures was defined as their salt taste threshold. The test was carried out by trained college students using a manual.

The other assessment was carried out by their mothers who rated their children's salt intake behavior using a questionnaire that included 7 questions related to their children's salt intake: daily food tastes, preference for salty food, preference for salty snacks, frequency of drinking soup per day, amount of table salt used, frequency of eating cup noodles per week and frequency of eating meals and snacks after school. If mothers thought that their children's behavior regarding salt intake showed a tendency toward more salt, the salt intake behavior score was one point, with the other responses receiving zero. The children's salt intake behavior score was obtained by summing these scores (minimum 0 , maximum 7 points), and the score was dichotomized to a low score group (0-3 points) and high score group (4-7 points).

\section{Statistical analysis}

Differences in mean age, height, weight, Rohrer index and estimated sodium excretion between boys and girls were compared using Student's $t$-test. Differences in taste preference and taste threshold between groups were compared using the chi-square test. Differences in estimated sodium excretion among three different taste preference groups were compared using ANOVA. If the differences among groups were statistically significant, differences between groups were compared using 
Bonferroni multiple comparison. Pearson's correlation coefficients were used to evaluate the association between the children's salt intake behavior score and estimated sodium excretion. Differences in estimated sodium excretion were compared between the low score group and high score group using ANCOVA, adjusting for age and Rohrer index. SPSS for WINDOWS, version 12.0 (SPSS Inc., Tokyo) was used for the analyses. Differences were considered significant at $p<0.05$.

\section{RESUlts}

Table 1 shows no difference between boys and girls regarding age, height, weight and Rohrer index. The average estimated sodium excretion of boys was significantly higher at $227 \mathrm{mmol}$ (s.D.: 65) than that of girls at $173 \mathrm{mmol}(44)$.

Table 2 shows the relationship between school children's own salty taste preference and their salt intake estimated by the amount of uri- nary sodium excretion. Children who thought that they liked a salty taste were not found to have a higher salt intake than those who disliked it. On the contrary, girls who disliked a salty taste had a significantly higher salt intake than those who liked it, with boys showing the same tendency.

Table 3 shows no relationship between school children's own salty taste preference and their salt taste threshold. The salt taste threshold of those who liked a salty taste was not higher than those who disliked it.

No association was found between the threshold level of salt taste and salt intake (Table 4). The salt intake of those who had a higher salt taste threshold was not higher than those with a lower salt taste threshold.

Table 5 shows the relationship between school children's salt intake and their eating

TABLE 1. Subjects' characteristics.

\begin{tabular}{lccc}
\hline & Boys & Girls & p-value \\
\hline$n$ & 91 & 108 & \\
Age & $11.2 \pm 0.5$ & $11.2 \pm 0.6$ & 0.956 \\
Height $(\mathrm{cm})$ & $142.0 \pm 6.7$ & $143.2 \pm 7.0$ & 0.260 \\
Weight $(\mathrm{kg})$ & $35.9 \pm 8.0$ & $36.1 \pm 7.8$ & 0.876 \\
Rohler index & $124.4 \pm 18.3$ & $122.0 \pm 16.7$ & 0.323 \\
Estimated sodium excretion (mmol/day) & $227 \pm 65$ & $174 \pm 44$ & 0.000 \\
\hline
\end{tabular}

Height and weight were measured according to standardized procedures at regular health checks stipulated by School Health Law. Estimated sodium excretion was estimated using Kawasaki's method (Kawasaki et al. 1993).

Data are the mean \pm S.D. $n$, number of subjects. Differences in variables between boys and girls were compared using Student's $t$-test.

TABLE 2. Relationship between children's own salty taste preference and salt intake.

\begin{tabular}{|c|c|c|c|c|c|c|}
\hline \multirow{2}{*}{ Salty taste preference } & \multicolumn{3}{|c|}{ Boys sodium (mmol/day) } & \multicolumn{3}{|c|}{ Girls sodium (mmol/day) } \\
\hline & $n$ & mean S.D. & p-value & $n$ & mean S.D. & p-value \\
\hline Dislike & 23 & $250 \pm 74$ & & 50 & $186 \pm 51$ & \\
\hline Not preference & 41 & $213 \pm 57 *$ & 0.085 & 33 & $166 \pm 32 *$ & 0.037 \\
\hline Like & 27 & $229 \pm 66$ & & 25 & $161 \pm 40 *$ & \\
\hline
\end{tabular}

Children's own salty taste preference was measured using a multiple-choice question: dislike, ordinary or like. Salt intake was estimated by urinary sodium excretion using Kawasaki's method (Kawasaki et al. 1993).

Differences in salt intake among three different taste preference groups were compared using ANOVA and Bonferroni multiple comparison. ${ }^{*} p<0.05$ difference from dislike group. 
TABLE 3. Relationship between children's own salty taste preference and salt taste threshold.

\begin{tabular}{|c|c|c|c|c|c|c|c|c|c|}
\hline \multicolumn{10}{|c|}{ Salt taste threshold } \\
\hline & \multicolumn{2}{|c|}{ Total } & \multicolumn{2}{|c|}{$0.6 \%$} & \multicolumn{2}{|c|}{$0.8 \%$} & \multicolumn{2}{|c|}{$1.0 \sim 1.6 \%$} & \multirow{2}{*}{ p-value } \\
\hline & $n$ & $(\%)$ & $n$ & $(\%)$ & $n$ & $(\%)$ & $n$ & $(\%)$ & \\
\hline \multicolumn{10}{|c|}{ Salty taste preference } \\
\hline Dislike & 73 & 100.0 & 43 & 58.9 & 16 & 21.9 & 14 & 19.1 & \\
\hline Not preference & 74 & 100.0 & 46 & 62.2 & 20 & 27.0 & 8 & 10.9 & 0.630 \\
\hline Like & 52 & 100.0 & 29 & 55.8 & 15 & 28.8 & 8 & 15.3 & \\
\hline
\end{tabular}

Children's own salty taste preference was measured using a multiple-choice question: dislike, ordinary or like. Salt taste threshold was the lowest salt concentration recognized as salty. It was measured by Salsave of $0.6 \%$ to $1.6 \%$ salt concentration.

$n$, number of subjects. Differences in taste preference and taste threshold between groups were compared using $\chi^{2}$ test.

TABLE 4. Relationship between children's threshold of salty taste and salt intake.

\begin{tabular}{rrrrrrrrr}
\hline \multirow{2}{*}{ Salt taste } & \multicolumn{3}{c}{ Boys sodium (mmol/day) } & & \multicolumn{3}{c}{ Girls sodium (mmol/day) } \\
\cline { 2 - 3 } & $n$ & mean & s.D. & p-value & & $n$ & mean s.D. & p-value \\
\hline $0.6 \%$ & 52 & $231 \pm 76$ & & & 66 & $174 \pm 43$ & \\
$0.8 \%$ & 26 & $214 \pm 51$ & 0.481 & & 25 & $171 \pm 48$ & 0.825 \\
$1.0 \sim 1.6 \%$ & 13 & $237 \pm 43$ & & & 17 & $180 \pm 46$ & \\
\hline
\end{tabular}

Salt taste threshold was the lowest salt concentration recognized as salty. It was measured by Salsave of $0.6 \%$ to $1.6 \%$ salt concentration. Salt intake was estimated by urinary sodiumt excretion using Kawasaki's method (Kawasaki et al. 1993).

Differences in salt intake among three different threshold groups were compared using ANOVA.

behavior observed by their mothers. Boys who liked salty food or who ate a cup noodle more than once a week ingested significantly more salt than those who did not like salty food or ate a cup noodle less than once per two weeks.

Regarding the relationship between the salt intake behavior score and salt intake, a significant relationship was shown in boys $(\mathrm{r}=0.282, p=$ $0.007)$ with a similar tendency shown in girls $(\mathrm{r}=$ $0.144, p=0.066$ ). After adjusting for age and Rohrer index, the high score group had a higher estimated salt intake than the low score group (Table 6).

\section{DiscuSsion}

To our knowledge, this is the first study that has suggested that children's salt intake may be accurately assessed by their mother's observation of their salt intake behavior; however, our hypothesis that children's own salty taste preference is associated with their salt intake was not proven, nor that children's own salty taste preference is associated with their salt taste threshold level. These negative results are consistent with previous studies that there is no relationship between the salt taste threshold and salt intake (Pangborn and Pecore 1982) or between salty taste preference and the salt taste threshold (Lauer et al. 1976). Pangborn and Pecore (1982) considered that few sensory measures, especially discrimination, sensitivity, perceived intensity, preference, and hedonic responses, are related to estimated salt intake, and Lauer et al. (1976) considered that salt taste preference is a phenomenon unrelated to the taste threshold of sodium chloride.

In addition to these possible reasons, two 
TABLE 5. Relationship between children's salt intake and their eating behaviors observed by their.

\begin{tabular}{|c|c|c|c|c|c|c|}
\hline \multirow{2}{*}{$\begin{array}{l}\text { Children's eating behavior } \\
\text { observed by mothers }\end{array}$} & \multicolumn{3}{|c|}{ Boys sodium (mmol/day) } & \multicolumn{3}{|c|}{ Girls sodium (mmol/day) } \\
\hline & $n$ & mean S.D. & $\mathrm{p}$-value & $n$ & mean S.D. & p-value \\
\hline \multicolumn{7}{|l|}{ Daily food taste } \\
\hline Bland taste & 48 & $221 \pm 69$ & 0.417 & 50 & $175 \pm 47$ & 0.840 \\
\hline Rich taste & 43 & $233 \pm 61$ & & 58 & $173 \pm 43$ & \\
\hline \multicolumn{7}{|l|}{ Preference for high salt content food } \\
\hline Dislike & 43 & $209 \pm 57$ & 0.011 & 38 & $165 \pm 32$ & 0.105 \\
\hline Like & 48 & $244 \pm 69$ & & 70 & $179 \pm 49$ & \\
\hline \multicolumn{7}{|l|}{ Preference for high salt content snack } \\
\hline Dislike & 9 & $201 \pm 43$ & 0.199 & 9 & $152 \pm 33$ & 0.133 \\
\hline Like & 82 & $230 \pm 67$ & & 99 & $176 \pm 45$ & \\
\hline \multicolumn{7}{|l|}{ Frequency of eating soup } \\
\hline Less than once/day & 67 & $225 \pm 65$ & 0.570 & 75 & $173 \pm 43$ & 0.857 \\
\hline More than twice/day & 24 & $234 \pm 68$ & & 33 & $175 \pm 47$ & \\
\hline \multicolumn{7}{|l|}{ Table salt seasoning use } \\
\hline Little & 41 & $223 \pm 65$ & 0.554 & 38 & $172 \pm 42$ & 0.718 \\
\hline Much & 50 & $231 \pm 66$ & & 70 & $175 \pm 46$ & \\
\hline \multicolumn{7}{|l|}{ Frequency of eating cup noodle } \\
\hline Less than once/ 2 weeks & 64 & $217 \pm 59$ & 0.017 & 97 & $174 \pm 45$ & 0.749 \\
\hline More than once/week & 27 & $252 \pm 74$ & & 11 & $170 \pm 35$ & \\
\hline \multicolumn{7}{|c|}{ Frequency of eating meals and snacks after school } \\
\hline Less than twice/day & 87 & $226 \pm 66$ & 0.570 & 103 & $171 \pm 43$ & 0.008 \\
\hline More than three times/day & 4 & $245 \pm 44$ & & 5 & $225 \pm 37$ & \\
\hline
\end{tabular}

Children's eating behaviors were assessed by their mothers using 7 questions related to children's salt intake. Salt intake was estimated using Kawasaki’s method (Kawasaki et al. 1993).

Differences between these two groups were compared using Student's $t$-test.

TABLE 6. Relationship between salt intake bahavior score and salt intake.

\begin{tabular}{|c|c|c|c|c|c|c|}
\hline \multirow{2}{*}{$\begin{array}{c}\text { Salt intake } \\
\text { behavior score }\end{array}$} & \multicolumn{3}{|c|}{ Boys sodium (mmol/day) } & \multicolumn{3}{|c|}{ Girls sodium (mmol/day) } \\
\hline & $n$ & mean S.D. & p-value & $n$ & mean S.D. & $\mathrm{p}$-value \\
\hline Low score group & 49 & $213 \pm 62$ & 0067 & 61 & $167 \pm 38$ & 0066 \\
\hline Hight score group & 42 & $244 \pm 62$ & 0.001 & 47 & $183 \pm 50$ & 0.000 \\
\hline
\end{tabular}

ANCOVA: adjusted for age and Rohler index.

If mothers thought that their children's behavior regarding salt intake showed a tendency to eat more salt, salt intake behavior score was one point; others had zero on 7- item questions. Salt intake behavior score was obtained by summing these scores. Low score group: 0-3 points. High score group: 4-7 points. Salt intake was estimated by urinary sodium excretion using Kawasaki's method (Kawasaki et al. 1993).

Differences in salt intake were compared between low score group and high score group using ANCOVA adjusting for age and Rohrer index. 
others may explain these negative results. First, there is a possibility that we were not able to measure the true salt taste threshold. We used Salsave, which had a taste recognition threshold for $\mathrm{NaCl}$ of $0.6 \%$ in our study. In other studies, the taste recognition threshold for $\mathrm{NaCl}$ was $0.35 \%$ (Okoro et al. 1998) or 0.04-0.12\% (Okamoto and Taguchi 1996). Because about $60 \%$ subjects recognized the salty taste in the $0.6 \%$ sample, the concentration of the test paper which measured the threshold might have been too high (Nishimoto et al. 1996, 2005). Second, we measured children's own salty taste preference using only one multiple choice question: dislike, no preference and like, but the reliability of the question was not examined. There is a possibility that we could not accurately assess the subjects' salty taste preference.

This study showed that school children's salt intake behavior observed by their mothers was related to children's salt intake. Children who were observed by their mother to have a liking for salty food ingested more salt than those who did not like salty food. This result may be explained if we consider that school children's salt intake behavior observed by their mothers was more reliable than children's own perception of liking salty food. This indicates the importance of a mother's role in reducing children's salt intake. Showing this result to mothers is expected to motivate them to educate their children to eat less salty food and snacks. Recently, salt intake has become dependent on the amount of salt added by food manufacturers rather than on salt added during cooking or at the table (Samara et al. 2002; Antonio 2000). In Finland, most salt intake derives from manufactured foods, such as bread, meat and fish products (Reinivuo 2007). In this study, more than $90 \%$ of subjects preferred high salt content snacks and the frequency of eating cup noodles was associated with salt intake. In addition to individual health education for children, the development of low-salt and reduced salt products, and clear food labeling are also important in consideration of the increased numbers of manufactured foods in Japan.

There are several limitations of this study.
First, we cannot reject the possibility that we could not accurately assess children's salty taste preference. Both the reliability of the question to school children asking about their own salty taste preference, and the reliability and validity of the questionnaire for their mothers asking them about their children's eating behavior in terms of salt intake were not verified. Second, salt intake should ideally be estimated by salt ingested in food, but our study estimated salt intake from the amount of urinary sodium excretion from the second morning voiding urine specimen.

As a future task, measurement of the salt taste threshold using a more sensitive method is needed. Development of a questionnaire with reliability and validity in order to assess children's salty taste preference is also required.

\section{Conclusion}

Children's salt intake may be accurately assessed by their mother's observation of their salt intake behavior. This study suggests the importance of a mother's role in salt restriction education for children.

\section{References}

Antonios, T.F.T. (2000) Salt intake in early life and cardiovascular risk. Acta Pediatr., 89, 397-398.

Beauchamp, G.K. \& Engelman, K.T. (1991) High salt intake, Sensory and behavioral factors. Hypertension, 17, 76-81.

Chobanian, A.V. \& Hill, M.E. (2000) National Heart. Lung and Blood Institute workshop sodium and blood pressure: critical review of current scientific evidence. Hypertension, 35, 858-863.

Danise, G. \& Simons, M. (1997) Diet and blood pressure in children and adolescents. Pedatric Nephrology, 11, 244-256.

Frost, C.D., Law, N.R. \& Wald, N.J. (1981) By how much dose dietary salt reduction lower blood pressure analysis of observational data within populations. BMJ, 202, 815-818.

Ikeda, M., Kasahara, M., Koizumi, A. \& Watanabe, T. (1986) Correlation of cerebrovascular disease standardized mortality ratios with dietary sodium and the sodium-potassium ratio among the Japanese population. Prev Med., 15, 46-59.

Intersalt Cooperative Research Group (1988) Intersalt: an international study of electrolyte excretion and blood pressure. Results for $24 \mathrm{~h}$ urinary sodium and potassium excretion. $B M J, 297,319-328$.

Kaplan, N.M. (2000) The dietary guideline for sodium: should we shake it up? No. Am. J. Clin. Nutr., 71, 1020-1026.

Kawasaki, T., Itoh, K., Uezono, K. \& Sasaki, H. (1993) A simple method for estimating $24 \mathrm{~h}$ urinary sodium and potassium excretion from second morning voiding urine specimen in adults. Clin. Exper. Pharmacol. Physiol., 20, 7-14. 
Lauer, R.M., Filer, L.J., Reiter, M.A. \& Clarke, W.R. (1976) Blood pressure, salt preference, salt threshold and relative weight. Am. J. Dis. Child., 130, 473-477.

Michael, H.A., Hillel, C. \& Shantha, M. (1998) Dietary sodium intake and mortality: the National Health and Nutrition Examination Survey (NHANES 1). Lancet, 9105, 781-785.

Ministry of Health, Labor and Welfare (2004) National Health and Nutrition Survey in 2004. Ministry of Health, Labor and Welfare. Daiichi Shuppan, Tokyo, pp. 78-79.

Nagata, C., Takatsuka, N., Shimizu, N. \& Shimizu, H. (2004) Sodium intake and risk of death from stroke in Japanese men and women. Stroke, 35, 1543-1547.

Nishimoto, K., Hirata, R., Egawa, M. \& Furuta, S. (1996) Clinical Evaluation of taste dysfunction using a saltimpregnated taste strip. ORL, 58, 258-261.

Nishimoto, K., Ohbori, J., Shimomura, T. \& Kurono, Y. (2005) Reproducibility of taste examination with Salsave: Control study for healthy volunteer. J. Stomatology, 17, 309-315. (In Japan)

Okoro, E.O., Uroghide, G.E. \& Jolayemi, E.T. (1998) Salt taste sensitivity and Blood pressure in adolescent school children in south Nigeria. East African Med. J., 75, 199-203.

Okoro, E.O., Brisibe, F.E., Jolayemi, E.T., Hadizath, L.I. \& Taimagari, G.E. (2000) Taste sensitibity to sodium chloride and sucrose in a group of adolescent children in Northern
Nigeria. Ethn Dis., 10, 53-59.

Okamoto, Y. \& Taguchi, T. (1996) Studies on the taste preference and threshold on elementary school children. Nihon Kaseigaku Zasshi, 47, 161-168. (In Japanese)

Pangborn, R.M. \& Pecore, S.D. (1982) Taste perception of sodium chloride in relation dietary intake of salt. Am. J. Clin. Nutr., 35, 510-520.

Reinivuo, H., Valsta, L., Laatikainen, T., Tuomilehto, J. \& Pietinen, P. (2007) Sodium in the Finnish diet: trends in dietary sodium intake and comparison between intake and 24-hour excretion of sodium. Eur. J. Clin. Nutr., 23, 27-36.

Samara, J.N., Anna, M.S. \& Barry, M.P. (2002) Trend in energy intake in U.S. between 1977 and 1996; Similar shift seen across age group. Obesity Res., 5, 370-378.

Serafin, M. (2004) Blood pressure and relates to sodium taste sensitivity. Pediatric Nephrol., 18, 431-431.

Tarcey, K. \& Linda, B. (1995) Effect of capsaicin desensitization on taste in humans. Physiol. Behav., 57, 421-429.

Tuomilehto, K., Puska, P. \& Tanskanen, A. (1981) A community-based study on the feasibility and effects of the reduction of salt intake in North Karelia, Finland. Acta Cardiol., 36, 83-104.

Zumkley, H. (1987) Taste Sensitivity for Sodium Chloride in Hypertension, Normoretensive and Hypertensive subjects. Nephron, 47(Suppl.), 132-134. 